\title{
Communication \\ Chemically Roughened, Sputtered Au Films with Trace-Loaded Manganese Oxide for both On-Chip and Off-Chip High Frequency Supercapacitors
}

\author{
Pai Lu *, Haitao Xue, Wentao Liu, Zhongbao Feng and Qiang Sun
}

Citation: Lu, P.; Xue, H.; Liu, W.; Feng, Z.; Sun, Q. Chemically Roughened, Sputtered Au Films with Trace-Loaded Manganese Oxide for both On-Chip and Off-Chip High Frequency Supercapacitors. Nanomaterials 2021, 11, 257. https:// doi.org/10.3390/nano11020257

Academic Editor:

Pedro Gómez-Romero

Received: 26 November 2020

Accepted: 16 January 2021

Published: 20 January 2021

Publisher's Note: MDPI stays neutral with regard to jurisdictional claims in published maps and institutional affiliations.
School of Metallurgy, Northeastern University, Shenyang 110819, Liaoning, China; xuehaitao2020@163.com (H.X.); wentaoliu2021@163.com (W.L.); fengzb@smm.neu.edu.cn (Z.F.); sunq@smm.neu.edu.cn (Q.S.)

* Correspondence: lup@smm.neu.edu.cn

\begin{abstract}
High frequency supercapacitors (HFSCs) are promising in alternating current line filtering and adaptable storage of high-frequency pulse electrical energy. Herein, we report a facile yet integrated-circuit-compatible fabrication of HFSC electrodes by combining chemical roughening of the sputtered metal $(\mathrm{Au})$ films and in situ trace loading of a pseudocapacitive material $\left(\mathrm{MnO}_{x}\right)$. The developed electrode fabrication route is versatile for different substrates, and is described with the application paradigms of both on-chip (with $\mathrm{Si} / \mathrm{SiO}_{2}$ substrate) and off-chip (without $\mathrm{Si} / \mathrm{SiO}_{2}$ substrate, with Ti substrate as an example in this study) HFSCs. With $\mathrm{Au} / \mathrm{MnO}$ films on $\mathrm{Si} / \mathrm{SiO}_{2}$ substrates as the working electrodes, the derived on-chip HFSC displayed satisfactory performance in high frequency applications (i.e., an areal capacitance of $131.7 \mu \mathrm{F} \mathrm{cm}-2$, a phase angle of $-78^{\circ}$, and a RC time constant of $0.27 \mathrm{~ms}$, at $120 \mathrm{~Hz}$ ).
\end{abstract}

Keywords: high frequency supercapacitor; thin film electrode; sputtering; oxidative etching; chemical roughening; trace loading

\section{Introduction}

Supercapacitors have been widely pursued due to their fast charging/discharging capabilities, which readily complement the electrochemical batteries used in high power applications [1,2]. Supercapacitors respond well in time scales of seconds [3]; however, when a very high frequency is applied (e.g., above $100 \mathrm{~Hz}$ ), most commercial supercapacitors behave more like resistors than capacitors due to their large internal resistance [4]. High frequency supercapacitors (HFSCs), i.e., supercapacitors which are required to handle high frequencies, were first reported in 2010 by Miller et al., who proposed their use to filter alternating current $(\mathrm{AC})$ at $120 \mathrm{~Hz}$, replacing conventional aluminum electrolytic capacitors (AECs) [5]. Thanks to their much higher capacitance compared to AECs, the application of HFSCs is expected to facilitate miniaturization. In recent years, HFSCs which respond well at above $100 \mathrm{~Hz}$ and even up to several thousands of $\mathrm{Hz}$ have been shown to effectively collect the pulse energy generated by renewable energy harvesters, outperforming all other electrochemical energy storage devices [6]. Motivated by the aforementioned potential for AC filtering and effective storage of high frequency pulse energy, HFSCs have been positioned at the frontier of research [7].

Due to the requirement of high frequency response, the design of HFSC electrodes is required to enable both superior electronic and ionic transport [8]. During the past decade, electrical double layer capacitive nanocarbons (graphene $\left(131 \mu \mathrm{F} \mathrm{cm} \mathrm{cm}^{-2}\right.$ at $\left.120 \mathrm{~Hz}\right)$ [9], carbon nanotubes (CNT, $601 \mu \mathrm{F} \mathrm{cm}{ }^{-2}$ at $\left.120 \mathrm{~Hz}\right)$ [10], porous carbon $\left(132 \mu \mathrm{F} \mathrm{cm}^{-2}\right.$ at $120 \mathrm{~Hz})$ [11]), and pseudocapacitive materials (conductive polymer $\left(270 \mu \mathrm{F} \mathrm{cm} \mathrm{c}^{-2}\right.$ at $120 \mathrm{~Hz})$ [12], MXene (300 $\mu \mathrm{F} \mathrm{cm}^{-2}$ at $\left.120 \mathrm{~Hz}\right)$ [13]) have been explored as electrode materials for HFSCs. Various proposed electrode designs (typically, vertically aligned graphene [14], a thin layered porous CNT framework [10], macroporous carbon [11], conductive polymer thin films [12], and MXene/CNT composite films with incorporated 
abundant pores [15]) have been shown to attain great high frequency response. However, these electrode fabrication routes involve high temperature processing (e.g., chemical vapor deposition of graphene at $1000{ }^{\circ} \mathrm{C}$, thermal transformation of precursors at $800-900{ }^{\circ} \mathrm{C}$ for macroporous carbon film preparation), or tedious, multistep wet chemical preparation (e.g., etching and purification of graphene or MXene sheets, followed by multistep solution filtration and troublesome film transfer), which are obstacles to large scale application and commercialization.

The R\&D of HFSCs is mainly aiming at enabling their application in electronics. Most recently, their potential application in the Internet of Things (IoTs) to power fast data transfer has aroused immense interest [16]. From this perspective, the development of a facile yet integrated-circuit (IC)-compatible electrode fabrication strategy $[17,18]$ is of significance for deriving circuit-integratable HFSCs and facilitating the realization of miniaturized and smart electronics. The currently available, laborsome strategies apparently cannot meet this demand. Herein, we propose a novel HFSC electrode fabrication strategy based on room temperature etching of sputtered Au film and in situ trace loading of capacitive manganese oxide. The whole production process could be readily implemented in the IC industry. Also, for the first time, we show that abundant pseudo-capacitive metal oxides can be employed in HFSCs as active materials when the electrode is appropriately designed.

\section{Experimental}

\subsection{HFSC Electrode Fabrication}

\subsubsection{Au Film Growth}

To build on-chip and off-chip HFSCs, commercially available $\mathrm{Si} / \mathrm{SiO}_{2}$ wafers (Silicon Materials, Kaufering, Germany) and Ti foils (Sinopharm Chemical Reagent Co., Ltd., Beijing, China) were respectively used as building substrates.

$\mathrm{Au}$ film growth on $\mathrm{Si} / \mathrm{SiO}_{2}$ wafers: $50 \mathrm{~nm} \mathrm{Cr}$ films as the buffer layers were first deposited onto $\mathrm{Si} / \mathrm{SiO}_{2}$ wafers by electron beam evaporation to enhance the adhesion. During the deposition, the base pressure range and working pressure range were maintained at $5 \times 10^{-7}$ to $1 \times 10^{-6}$ Torr, and $1 \times 10^{-6}$ to $5 \times 10^{-6}$ Torr, respectively. A sensor-based digital system allowed precise control over the deposition rate, i.e., around $0.04 \mathrm{~nm} \mathrm{~s}^{-1}$. Afterwards, Au films with a thickness of $100 \mathrm{~nm}$ were deposited via room temperature DC sputtering at $35 \mathrm{~W}$. The deposition rate was controlled at around $0.06 \mathrm{~nm} \mathrm{~s}^{-1}$ by a sensor-based digital system.

The same Au DC sputtering process was applied for Au film growth on $\mathrm{Ti}$ foils, except for that no buffer layers were employed.

\subsubsection{Oxidative Etching}

The sputtered Au films on different substrates were exposed to $0.02 \mathrm{M} \mathrm{KMnO}_{4}$ solution for $14-16 \mathrm{~h}$ at room temperature. Afterwards, the obtained electrodes were cleaned with deionized water and dried in $\mathrm{N}_{2}$.

\subsection{HFSC Device Assembly}

Two identical electrodes were assembled in a typical sandwich configuration, with glass fiber as the separator and $1 \mathrm{M} \mathrm{Na}_{2} \mathrm{SO}_{4}$ as the electrolyte. Parafilm was used to package the device to avoid leakage of the electrolyte.

\subsection{Material Characterization and Electrochemical Measurement}

A scanning electron microscope (SEM) (FEI Quanta250FEG, Hilsboro, OR, USA) and atomic force microscope (AFM) (Bruker MultiMode 8, Billerica, MA, USA) were used to characterize the morphologies and surface roughness. An X-ray photo-electron spectroscopy (XPS) (Thermo Scientific ESCALAB 250 system, Waltham, MA, USA) measurement was performed to analyze the chemical elements.

Three-electrode measurements and testing of the full cells were conducted using a CHI 660E potentiostat (CHI, Shanghai, China). For cyclic voltammogram (CV) measure- 
ments, the electrochemical windows were maintained at $0-0.8 \mathrm{~V}$ relative to $\mathrm{Ag} / \mathrm{AgCl}$ (saturated $\mathrm{KCl}$ ) reference electrode. Electrochemical impedance spectroscopy (EIS) was measured with an amplitude of $5 \mathrm{mV}$ at the open circuit potential.

\section{Results and Discussion}

The proposed electrode fabrication was inspired by the oxidative etching of $\mathrm{Au}$ by $\mathrm{KMnO}_{4}$ [19]. The slow oxidation of $\mathrm{Au}^{0}$ to soluble $\mathrm{Au}^{3+}$ resulted in the chemical roughening of the sputtered Au films. Figure 1a,d show that the DC sputtering deposited a pristine $\mathrm{Au}$ film $(\mathrm{P}-\mathrm{Au})$, comprising Au nano-islands with the lateral size ranging from 10 to $40 \mathrm{~nm}$, according to the classical island growth mode, and a maximum surface roughness of $4 \mathrm{~nm}$. The etching of Au nano-islands was revealed by the AFM characterization of the chemically treated $\mathrm{Au}(\mathrm{T}-\mathrm{Au}$ ) film (Figure $\mathrm{1b}$ ), which clearly showed that the surface roughness had been greatly enhanced after exposing the sputtered P-Au to $\mathrm{KMnO}_{4}$ solution, with a maximum surface roughness of $15 \mathrm{~nm}$. Figure 1e shows that the oxidative etching preferentially took place at the grain boundary sites, which led to the formation of deeper trenches between the Au nano-islands, representing enhanced roughness. Accompanied with the oxidative etching, the concurrent reduction of $\mathrm{KMnO}_{4}$ resulted in the formation of manganese oxide $\left(\mathrm{MnO}_{x}\right)$ in situ. Benefiting from the slow redox rate of $\mathrm{Au}$ and $\mathrm{KMnO}_{4}$, a trace loading of $\mathrm{MnO}_{x}$ onto the Au nano-islands could be realized. The inset in Figure 1e shows that very tiny $\mathrm{MnO}_{x}$ nano-units were sparsely distributed on the $\mathrm{Au}$ islands. Figure 1c describes the process schematically. The trace $\mathrm{MnO}_{x}$ product was examined by XPS (Figure 1f-h). The Au $4 \mathrm{f}$ spectrum (Figure 1f) with two peaks at $83.9 \mathrm{eV}\left(\mathrm{Au} 4 \mathrm{f}_{7 / 2}\right)$ and $87.6 \mathrm{eV}\left(\mathrm{Au} 4 \mathrm{f}_{5 / 2}\right)$ corresponded to the $\mathrm{Au}^{0}$ substrate [20]. The formation of $\mathrm{MnO}_{x}$ was confirmed by the XPS signals from the Mn $2 \mathrm{p}$ (Figure $1 \mathrm{~g}$ ) and $\mathrm{O} 1 \mathrm{~s}$ (Figure $1 \mathrm{~h}$ ) orbits. The peaks with binding energies of $642.1 \mathrm{eV}$ and $653.5 \mathrm{eV}$ were attributed to the $\mathrm{Mn} 2 \mathrm{p}_{3 / 2}$ and $\mathrm{Mn} \mathrm{2} \mathrm{p}_{1 / 2}$ spin-orbit doublets, respectively, for $\mathrm{MnO}_{2}$, which demonstrated that the main valence state of $\mathrm{MnO}_{\mathrm{x}}$ was IV [21]. Inferred from the $\mathrm{O} 1 \mathrm{~s}$ spectrum, $\mathrm{Mn}-\mathrm{O}-\mathrm{Mn}$ $(529.6 \mathrm{eV})$ in manganese oxide, and $\mathrm{Mn}-\mathrm{O}-\mathrm{H}(531.4 \mathrm{eV})$ in manganese hydroxide had both been incorporated [22].

From the CV comparison result in the three-electrode test (Figure 2a), it was found that the T-Au electrode with loaded trace $\mathrm{MnO}_{x}$ displayed typical capacitive behavior and much larger integrated capacitive current than $\mathrm{P}-\mathrm{Au}$; this was attributed to the increased number of electrochemical active sites for electrical double layer capacitance via surface roughening and the grown pseudo-capacitive $\mathrm{MnO}_{x}$ on the Au nano-islands. An areal capacitance of $380 \mu \mathrm{F} \mathrm{cm}^{-2}$ was achieved at $100 \mathrm{mV} \mathrm{s}^{-1}$ (capacitance calculation, presented in Supplementary Materials). Figure $2 \mathrm{~b}$ indicates that an ideal, rectangular shape of $\mathrm{CV}$ curves could be maintained in a wide range of $\mathrm{CV}$ sweeping rates in the three-electrode test. With the $\mathrm{T}-\mathrm{Au} / \mathrm{MnO}_{x}$ on $\mathrm{Si} / \mathrm{SiO}_{2}$ substrates as the electrodes, the electrochemical performance of the on-chip full cell was studied. Generally, the phase angle at $120 \mathrm{~Hz}$ is significant for $60 \mathrm{~Hz}$ AC response. The assembled on-chip full cell showed a phase angle of $-78^{\circ}$ at $120 \mathrm{~Hz}$ (Figure 2c), which was very close to that of commercial AECs for AC filtering (typically, with a phase angle of around $-80^{\circ}$ at $120 \mathrm{~Hz}$ [12]), indicating its high frequency response capability. The resistor-capacitor $(\mathrm{RC})$ time constant $\left(\tau_{\mathrm{RC}}\right)$ was calculated to be $0.27 \mathrm{~ms}$, i.e., much smaller than $8.3 \mathrm{~ms}$ (for $120 \mathrm{~Hz}$ filtering). This $\tau_{\mathrm{RC}}$ also confirmed its promising high frequency handling capability. The measured Nyquist plots (Figure 2d) revealed a low equivalent series resistance (ESR) of the on-chip HFSC $\left(0.38 \Omega \mathrm{cm}^{2}\right)$. To the best of our knowledge, this is the lowest ESR of any supercapacitor based on nonconductive pseudocapacitive active materials to date. The low ESR is beneficial for the fast response; we attributed this to two aspects: (1) a very good chemical bonding between $\mathrm{MnO}_{x}$ and $\mathrm{Au}$, realized by the redox reaction (between $\mathrm{Au}$ and $\mathrm{KMnO}_{4}$ ) -promoted deposition, and (2) the sparse loading of very tiny $\mathrm{MnO}_{x}$ nano-units facilitating electrolyte access and assisting in the reduction of the material resistance by shrinking. The specific real and imaginary capacitances of this on-chip HFSC are plotted versus frequency in Figure 2e. Given the frequency $\left(f_{0}=2359 \mathrm{~Hz}\right)$ at the maximum $\mathrm{C}^{\prime \prime}$, the relaxation time 
constant $\tau_{0}\left(=1 / \mathrm{f}_{0}\right)$ was derived, i.e., $424 \mu \mathrm{s}$, which was the minimum time to discharge its maximum energy with an efficiency $\geq 50 \%$ [23]. High $\mathrm{f}_{0}$ and small $\tau_{0}$ are also indicators of fast frequency response. The $\tau_{0}$ of our on-chip HFSC was much smaller than those of commercial supercapacitors based on activated carbon $(>200 \mathrm{~ms})$ [24]. The area capacitance as a function of frequency of this HFSC is presented in Figure 2f. At $120 \mathrm{~Hz}$, the HFSC was capable of delivering an areal capacitance of $131.7 \mu \mathrm{F} \mathrm{cm}^{-2}$, which is comparable with most nanocarbon-based HFSCs [4-6,9-11]; however the electrode fabrication technique used in the present study is much easier to scale up. The areal capacitance can be kept at around $100 \mu \mathrm{F} \mathrm{cm}^{-2}$, even when the on-chip HFSC is operated at up to thousands of $\mathrm{Hz}$. Therefore, the proposed HFSC demonstrates promising potential to collect pulsed energy from various renewable energy harvesters with extremely high frequency output [4].



Figure 1. AFM characterization of sputtered $\mathrm{Au}$ film on $\mathrm{Si} / \mathrm{SiO}_{2}(\mathbf{a})$ before and (b) after oxidative etching. (c) Sketch of the electrode formation via oxidative etching and in situ trace loading of $\mathrm{MnO}_{x}$. SEM characterization of (d) P-Au and (e) T-Au/ $\mathrm{MnO}_{x}$ (inset scale bar is $100 \mathrm{~nm}$ ). XPS characterization of T-Au/ $\mathrm{MnO}_{x}$ electrode for (f) Au $4 \mathrm{f}$ orbit, (g) Mn 2p orbit, and (h) O 1s orbit. 



Figure 2. Three-electrode measurement: (a) CV comparison of $\mathrm{P}-\mathrm{Au}$ and $\mathrm{T}-\mathrm{Au} / \mathrm{MnO}_{x}$ at $100 \mathrm{mV} \mathrm{s}{ }^{-1}$, (b) CV measurements of T-Au/ $\mathrm{MnO}_{x}$ at varying scan rates. Full cell measurement of on-chip HFSCs: (c) Phase angle versus frequency, (d) Nyquist plot, (e) Plots of the real or imaginary part of the specific capacitance as a function of frequency, (f) Areal specific capacitance versus frequency.

To prove the versatility, i.e., in terms of the choice of substrate, of the proposed electrode fabrication technique, we described an off-chip HFSC with the $\mathrm{KMnO}_{4}$-treated $\mathrm{Au}$ films on Ti substrates as the electrodes. Figure 3 shows the morphologies of the $\mathrm{Au} / \mathrm{Ti}$ film before and after the oxidative etching. The trace-loading of $\mathrm{MnO}_{x}$ was confirmed in the same way as that of the on-chip HFSC electrodes. The high frequency response capabilities of the assembled off-chip HFSC are presented in Figure 4, with a phase angle of $-77^{\circ}$ at $120 \mathrm{~Hz}$ (Figure $4 \mathrm{a}$ ), and an ESR of $1.24 \Omega \mathrm{cm}^{2}$ (Figure $4 \mathrm{~b}$ ). The $\tau_{0}$ derived at $\mathrm{f}_{0}$ in Figure $4 \mathrm{c}$ was $1000 \mu \mathrm{s}$. An areal capacitance of $112.2 \mu \mathrm{F} \mathrm{cm}{ }^{-2}$ at $120 \mathrm{~Hz}$ was achieved. All the performance indicators indicated the high frequency handling capability of this off-chip HFSC. Compared with existing on-chip HFSCs, the off-chip HFSC exhibited a slightly larger ESR, which may have been due to the difference in substrate geometry. Commercial Ti foil without any surface modification is not as flat and smooth as $\mathrm{Si}$ wafer. The deposition of a $100 \mathrm{~nm}$ thick Au film on a coarse Ti foil could lead to the formation of cracks and local discontinuity within the Au film, or even cavities between $\mathrm{Au}$ and the underlying Ti substrate. As a result, the electron transfer pathway could be prolonged, and $\mathrm{Au} / \mathrm{Ti}$ interphase resistance could be generated. All these factors are obstacles to lowering the ESR. It is expected that this problem may be overcome by surface treatment of the metal substrates. 

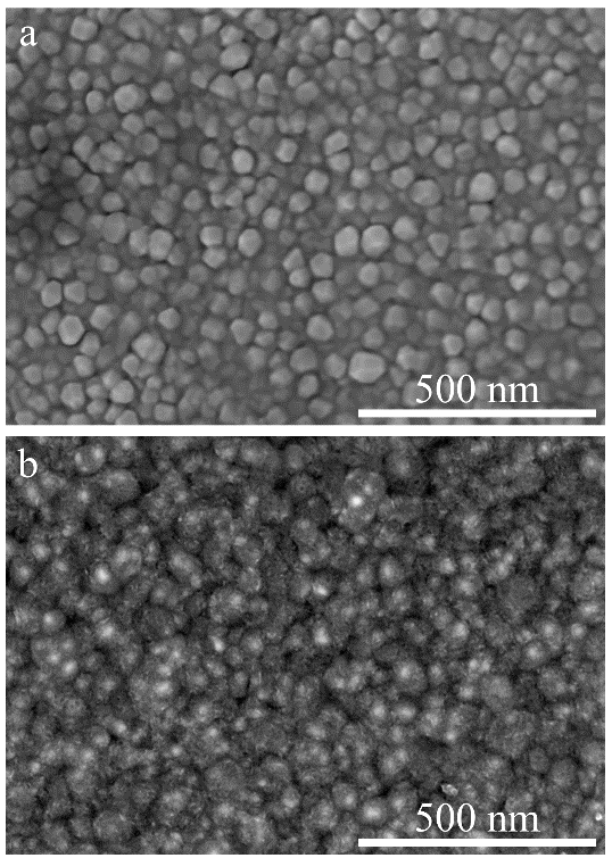

Figure 3. SEM characterization of sputtered Au film on Ti foil (a) before and (b) after the oxidative etching.
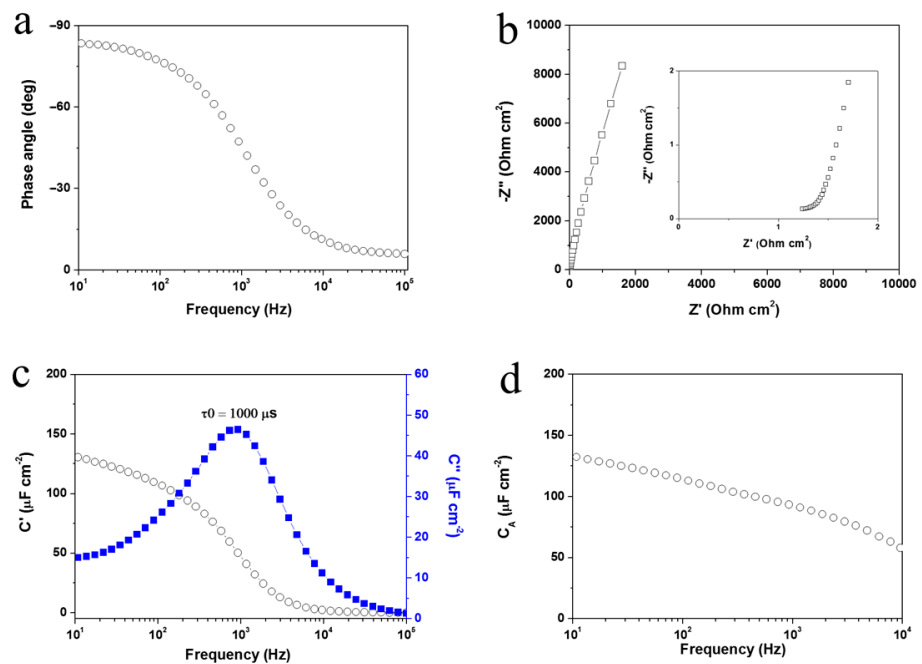

Figure 4. Full cell measurement of off-chip HFSCs with Ti foils as the substrates: (a) Phase angle versus frequency, (b) Nyquist plot, (c) Plots of the real or imaginary part of the specific capacitance as a function of frequency, (d) Areal specific capacitance versus frequency.

\section{Conclusions}

In this study, we developed a facile, room temperature fabrication technique for HFSC electrodes. A slow redox reaction between $\mathrm{Au}$ and $\mathrm{KMnO}_{4}$ is the basis for deriving enhanced HFSC performance via chemical roughening of sputtered Au films to create increased surface area, and trace loading of $\mathrm{MnO}_{x}$ nano-units as the active material to contribute to pseudo-capacitance as well as reduce the material resistance by size shrinking. The DC sputtering of Au films and subsequent oxidative etching could be readily implemented in the IC industry. The reported electrode fabrication technique is also versatile, i.e., in terms of the choice of substrate, which demonstrates its wide adaptability.

Supplementary Materials: The detailed capacitance calculation is available online at https:/ / www. mdpi.com/2079-4991/11/2/257/s1. 
Author Contributions: P.L.: Conceptualization, Methodology, Supervision, Project administration, Writing-Original Draft. H.X.: Investigation. W.L.: Investigation. Z.F.: Formal analysis, Writing-Review \& Editing, Project administration. Q.S.: Formal analysis, Writing-Review \& Editing, Project administration. All authors have read and agreed to the published version of the manuscript.

Funding: This research was funded by the NATIONAL NATURAL SCIENCE FOUNDATION OF CHINA, grant number 51902044, 51904060, 21503033, the NATURAL SCIENCE FOUNDATION OF LIAONING PROVINCE, grant number 20180510026, the OPEN FUNDS OF THE STATE KEY LABORATORY OF RARE EARTH RESOURCE UTILIZATION, grant number RERU2019015, and the FUNDAMENTAL RESEARCH FUNDS FOR THE CENTRAL UNIVERSITIES, grant number N182503031, N2025021.

Conflicts of Interest: The authors declare no conflict of interests.

\section{References}

1. Wang, Z.S.; Shen, J.D.; Liu, J.; Xu, X.J.; Liu, Z.B.; Hu, R.Z.; Yang, L.C.; Feng, Y.Z.; Shi, Z.C.; Ouyang, L.Z.; et al. Self-supported and flexible sulfur cathode enabled via synergistic confinement for high-energy-density lithium-sulfur batteries. Adv. Mater. 2019, 31, 1902228. [CrossRef] [PubMed]

2. Si, W.P.; Yan, C.; Chen, Y.; Oswald, S.; Han, L.Y.; Schmidt, O.G. On chip, all solid-state and flexible micro-supercapacitors with high performance based on $\mathrm{MnO}_{x} / \mathrm{Au}$ multilayers. Energy Environ. Sci. 2013, 6, 3218-3223. [CrossRef]

3. Pan, Z.H.; Qiu, Y.C.; Yang, J.; Ye, F.M.; Xu, Y.J.; Zhang, X.Y.; Liu, M.N.; Zhang, Y.G. Ultra-endurance flexible all-solid-state asymmetric supercapacitors based on three-dimensionally coated $\mathrm{MnO}_{\mathrm{x}}$ nanosheets on nanoporous current collectors. Nano Energy 2016, 26, 610-619. [CrossRef]

4. Fan, Z.Y.; Islam, N.; Bayne, S.B. Towards kilohertz electrochemical capacitors for filtering and pulse energy harvesting. Nano Energy 2017, 39, 306-320. [CrossRef]

5. Miller, J.R.; Outlaw, R.A.; Holloway, B.C. Graphene double-layer capacitor with ac line-filtering performance. Science 2010, 329, 1637-1639. [CrossRef]

6. Islama, N.; Li, S.Q.; Ren, G.F.; Zu, Y.J.; Warzywoda, J.; Wang, S.; Fan, Z.Y. High-frequency electrochemical capacitors based on plasma pyrolyzed bacterial cellulose aerogel for current ripple filtering and pulse energy storage. Nano Energy 2017, 40, 107-114. [CrossRef]

7. Zhang, C.G.; Du, H.Z.; Ma, K.; Yuan, Z.H. Ultrahigh-rate supercapacitor based on carbon nano-onion/graphene hybrid structure toward compact alternating current filter. Adv. Energy Mater. 2020, 10, 2002132. [CrossRef]

8. Miller, J.R. Perspective on electrochemical capacitor energy storage. Appl. Surf. Sci. 2018, 460, 3-7. [CrossRef]

9. Premathilake, D.; Outlaw, R.A.; Parler, S.G.; Butler, S.M.; Miller, J.R. Electric double layer capacitors for ac filtering made from vertically oriented graphene nanosheets on aluminum. Carbon 2017, 111, 231-237. [CrossRef]

10. Rangom, Y.; Tang, X.; Nazar, L.F. Carbon nanotube-based supercapacitors with excellent ac line filtering and rate capability via improved interfacial impedance. ACS Nano 2015, 9, 7248-7255. [CrossRef]

11. Zhao, M.; Nie, J.H.; Li, H.; Xia, M.Y.; Liu, M.Y.; Zhang, Z.L.; Liang, X.Q.; Qi, R.J.; Wang, Z.L.; Lu, X.M. High-frequency supercapacitors based on carbonized melamine foam as energy storage devices for triboelectric nanogenerators. Nano Energy 2019, 55, 447-453. [CrossRef]

12. Wu, M.M.; Chi, F.Y.; Geng, H.Y.; Ma, H.Y.; Zhang, M.; Gao, T.T.; Li, C.; Qu, L.T. Arbitrary waveform AC line filtering applicable to hundreds of volts based on aqueous electrochemical capacitors. Nat. Commun. 2019, 10, 2855. [CrossRef] [PubMed]

13. Jiang, Q.; Kurra, N.; Maleski, K.; Lei, Y.J.; Liang, H.F.; Zhang, Y.Z.; Gogotsi, Y.; Alshareef, H.N. On-chip MXene microsupercapacitors for AC-line filtering applications. Adv. Energy Mater. 2019, 9, 1901061. [CrossRef]

14. Li, J.; Gao, H.; Miller, J.R.; Outlaw, R.A.; Butler, S.; Lian, K. Study of solid alkaline electrolyte under high temperatures and its application in electrochemical capacitors for AC line-filtering. J. Power Sources 2019, 417, 145-149. [CrossRef]

15. Xu, S.X.; Liu, W.; Hu, B.M.; Wang, X.H. Circuit-integratable high-frequency micro supercapacitors with filter/oscillator demonstrations. Nano Energy 2019, 58, 803-810. [CrossRef]

16. He, H.X.; Zhao, T.M.; Guan, H.Y.; Zhong, T.Y.; Zeng, H.; Xing, L.L.; Zhang, Y.; Xue, X.Y. A water-evaporation-induced self-charging hybrid power unit for application in the Internet of Things. Sci. Bull. 2019, 64, 1409-1417. [CrossRef]

17. Lu, P.; Mueller, L.; Hoffmann, M.; Chen, X.Y. Taper silicon nano-scaffold regulated compact integration of $1 \mathrm{D}$ nanocarbons for improved on-chip supercapacitor. Nano Energy 2017, 41, 618-625. [CrossRef]

18. Lu, P.; Ohlckers, P.; Mueller, L.; Leopold, S.; Hoffmann, M.; Grigoras, K.; Ahopelto, J.; Prunnila, M.; Chen, X.Y. Nano fabricated silicon nanorod array with titanium nitride coating for on-chip supercapacitors. Electrochem. Commun. 2016, 70, 51-55. [CrossRef]

19. Monga, A.; Pal, B. Influence of oxidative etching of Au nanostructures by $\mathrm{KMnO}_{4}$ on its surface morphology. J. Ind. Eng. Chem. 2015, 31, 223-230. [CrossRef]

20. Liu, J.S.; Hu, Y. Characterization of manganese oxides/Au nanocompsite thin films for supercapacitor. Int. J. Electrochem. Sci. 2013, 8, 9231-9241.

21. Abdur, R.; Kim, K.; Kim, J.H.; Lee, J. Electrochemical behavior of manganese oxides on flexible substrates for thin film supercapacitors. Electrochim. Acta 2015, 153, 184-189. [CrossRef] 
22. Chigane, M.; Ishikawa, M. Manganese oxide thin film preparation by potentiostatic electrolyses and electrochromism. J. Electrochem. Soc. 2000, 147, 2246-2251. [CrossRef]

23. Taberna, P.L.; Simon, P.; Fauvarque, J.F. Electrochemical characteristics and impedance spectroscopy studies of carbon-carbon supercapacitors. J. Electrochem. Soc. 2003, 150, A292-A300. [CrossRef]

24. Pech, D.; Brunet, M.; Taberna, P.; Simon, P.; Fabre, N.; Mesnilgrente, F.; Conedera, V.; Durou, H. Elaboration of a microstructured inkjet-printed carbon electrochemical capacitor. J. Power Sources 2010, 195, 1266-1269. [CrossRef] 